\title{
TERRORISMO, MEDO E RECRUDESCIMENTO DO CONTROLE: TRAÇOS DA POLÍTICA PUNITIVA NO MUNDO CONTEMPORÂNEO
}

\author{
Debora Regina Pastana ${ }^{1}$
}

\begin{abstract}
Resumo
0 tema central deste artigo é o investimento crescente no combate ao que se convencionou chamar de terrorismo pelas democracias contemporâneas, o que contribui para consolidar, ao menos no Ocidente, a figura do "Estado punitivo". Inserido nas recentes reflexões sociológicas de Chomsky, Wacquant, Garland e Bauman, entre outros, esse tema é ainda pouco discutido pela comunidade acadêmica brasileira. 0 atual arranjo capitalista se generaliza quase que instantaneamente em todo 0 globo atrelando, de forma paradoxal, a defesa dos ideais democráticos com a necessidade de políticas autoritárias de controle social. A defesa constante da "guerra ao terror", agindo como elo hegemônico consensual, amplia a defasagem entre o formal e o real, bem como a utilização simbólica dos instrumentos jurídicos de controle.
\end{abstract}

Palavras-chave: Medo. Terrorismo. Democracia. Estado punitive.

\section{TERRORISM, FEAR AND STRICT CONTROL: TRAITS OF PUNITIVE POLICY IN CONTEMPORARY WORLD}

\begin{abstract}
This article explores the increasing investment in combating the so called terrorism by contemporary democracies. Such measure consolidates, at least in the West, the figure of the «punitive state.» Inserted in the recent sociological reflections of Chomsky, Wacquant, Garland, and Bauman, among others, this theme still lacks further

\footnotetext{
${ }^{1}$ Professora do Instituto de Ciências Sociais e do Programa de Pós-Graduação em Ciências Sociais da Universidade Federal de Uberlândia - UFU. Colaboradora do Programa de Pós-Graduação em Direito Público da UFU, Brasil. deborarepastana@bol.com.br
} 
discussion in Brazilian academic community. The current capitalist arrangement is generalized almost instantaneously across the globe tying, paradoxically, the defense of democratic ideals with the need for authoritarian policies of social control. The constant defense of the «war on terror», acting as an hegemonic consensus link, broadens the gap between formal and real, and the use of token legal instruments of control.

Keywords: Fear. Terrorism. Democracy. State punitive.

\section{INTRODUÇÃO}

Devemos resistir à retórica do medo irracional com a qual governos como os do presidente Bush e do primeiro-ministro Blair buscam justificar uma política imperial para o mundo. Exceto como metáfora, não pode haver algo como a "guerra contra o terror" ou o "terrorismo", mas apenas contra atores políticos particulares que o empregam como tática, não como programa. Como tática, o terror é indiscriminado e moralmente inaceitável, quer seja usado por países, quer por grupos não oficiais. A Cruz Vermelha Internacional reconbece a maré montante da barbárie ao condenar ambos os lados na Guerra do Iraque. Há também muito medo de que pequenos grupos terroristas possam empregar agentes biológicos letais; mas, infelizmente, bá muito menos medo com relação aos perigos maiores e imprevisiveis que surgirão se e quando a nova e crescente capacidade científica de manipular os processos vitais, inclusive a vida bumana, escapar ao controle, o que certamente ocorrerá, Contudo, são irrisórios os perigos reais para a estabilidade do mundo, ou para qualquer país estável, que decorrem das atividades das redes terroristas pan-islâmicas contra as quais os Estados Unidos proclamaram sua guerra global, ou mesmo da soma de todos os movimentos terroristas que atuam hoje, qualquer que seja o lugar. Embora eles matem muito mais gente do que seus predecessores - mas muito menos do que os Estados -, o risco de vida que causam é mínimo do ponto de vista estatístico. E, do ponto de vista da agressão militar eles praticamente não contam. A menos que esses grupos ganhassem acesso a armas nucleares - o que não é impensável, mas não chega a ser uma perspectiva imediata -, o terrorismo pede cabeça fria, e não bisteria (HOBSBAWM, 2010, p. 46)

\footnotetext{
A ssim como Hobsbawm, Bauman (2008, p. 10) também nos alerta que "0 medo derivado é facilmente ‘desacoplado' dos perigos que o causam”. É fato que o medo sempre acompanhou o homem, haja vista sua busca permanente de coesão e organização em grupo para se fortalecer e se proteger, vale dizer, para enfrentar e eliminar as causas do medo. Sobre o assunto afirma Delumeau (1999, p. 18-20) que a sensibilidade ao medo é um componente maior da experiência humana, a despeito dos esforços para superá-la. Delumeau, inclusive, identifica
} 
algumas formas de medos coletivos ocidentais e afirma que, independente do motivo que causa o medo, a necessidade de segurança é fundamental e está na base da afetividade e da moral humanas. Contudo, como adverte Bauman (2008, p. 10), "as reações defensivas ou agressivas resultantes, destinadas a mitigar o medo, podem ser dirigidas para longe dos perigos realmente responsáveis pela suspeita da insegurança".

Exemplo marcante dessa advertência é a universalização do terror que se inicia no século XXI, em outras palavras, o temor social exacerbado relacionado às práticas violentas perpetradas por facções de índole regionalista e/ou religiosa. Os ataques ocorridos em 11 de setembro de 2001 no Word Trade Center, em Nova York, e na sede do Pentágono, em Washington, representam o marco de um novo paradigma político não apenas para os EUA, mas para todo o Ocidente. Tal modelo é traduzido não apenas em um exercício autoritário, mas, acima de tudo, numa atuação antidemocrática hegemonicamente reconhecida como necessária. A conseqüência imediata é a restrição das liberdades civis em nome da segurança coletiva.

Como se observa, o argumento central aqui proposto é o investimento crescente no combate ao terrorismo ${ }^{2}$ pelas grandes potências ocidentais neste início de século, contribuindo, assim, para consolidar posturas políticas punitivas em várias partes do globo. Sob esse prisma se materializa a figura do Estado Punitivo que, nas palavras de Wacquant (2001, p. 7), caracteriza-se por diminuir

\footnotetext{
${ }^{2} 0$ termo terrorismo adquiriu grande relevância política nesse início do século XXI. Tem sido proclamado pelas grandes potências globais como principal ameaça à humanidade, sendo cada vez mais evidente a preocupação mundial relacionada ao terror. No entanto, é justamente a imprecisão do termo que possibilita seu uso político. Nesse artigo, o foco não é elucidar as várias explicações teóricas acerca de tema tão controverso. Também não objetiva conceituar terrorismo, tampouco abordar uma perspectiva teórica sobre o assunto. 0 que chama atenção para observação é justamente o uso difuso do termo, vale dizer, a explicação simplista de inúmeros eventos violentos reduzidos arbitrariamente à condição de terroristas. Ainda assim, é importante ressaltar que embora haja referências a atos terroristas desde a antiguidade, estamos vivenciando nos dias atuais uma série de atos violentos partindo de diferentes grupos com motivações também distintas. Laqueur (1996) reconhece tais diferenças, no entanto observa também algumas similitudes. Ao destacar a natureza globalizada de tais atentados prefere denominá-los de terrorismos pós-modernos. Segundo o autor, o velho terrorismo, datado principalmente do final do século XIX e início do XX, era caracterizado por organizações políticas (anarquistas, nacionalistas ou mesmo socialistas) com projetos bem definidos e propagados. 0 terrorismo pós-moderno, por sua vez, não tem um objetivo político explícito, embora procure chamar a atenção da mídia para seu potencial destrutivo, ainda que seus argumentos e proposições não estejam satisfatoriamente demonstrados. Esse novo terrorismo não estaria, portanto, preocupado com legitimidade (LAQUEUR, 1996).
} 
suas prerrogativas na frente econômica e social e por aumentar suas missões em matéria de segurança, "subitamente relegada à mera dimensão criminal".

Mas o que torna uma política unicamente punitiva? Em outras palavras, o que é que poderia justificar a descrição de uma trajetória sócio-cultural como punitiva?

A resposta é mais complexa do que parece. A "punitividade", de fato, em parte é um juízo comparativo acerca da "severidade" das penas com relação às medidas penais precedentes, em parte depende dos objetivos e das justificativas das medidas penais, assim como também da maneira pela qual a medida é apresentada ao público. As novas medidas que aumentam o nível das penas, reduzem os tratamentos penitenciários, ou impõem condições mais restritivas aos delinqüentes colocados em liberdade condicional ou vigiada [...] podem ser consideradas "punitivas", pois aumentam com relação a um ponto de referência anterior (GARLAND, 1999, p. 60).

Enfim, essa nova configuração política evidencia o investimento cada vez maior dos Estados em ações repressivas e severas, e explicita nítidos contornos de um "Estado punitivo" que se ajustam ao atual panorama econômico e social externado pelo recente modelo capitalista de desenvolvimento. É justamente essa associação que irá determinar um novo enfoque nas reflexões sobre o controle social em nível global, ou mesmo nacional. É, portanto, essencial poder identificar posturas ordinariamente punitivas que caracterizam o atual momento político.

Assim, o presente artigo não trata de um tipo especifico de terrorismo, tampouco de um evento particular, analisa-se, ao contrário, a repercussão política e cultural percebida após os atentados de 11/09. 0 uso arbitrário do controle penal em nome da segurança nacional, muitas vezes suprimindo direitos civis e violando direitos humanos parece ser o retrato da política contemporânea. Essa constatação é o objeto de estudo.

\section{DE SETEMbro: MARCo dA POlÍTICA PUNITIVA CONTEMPORÂNEA}

Ainda sob o impacto dos ataques de 11/09, o Congresso norte-americano aprovou, por uma esmagadora maioria (98 votos a 1 no Senado, e 357 a 66 na Câmara dos Deputados), em outubro de 2001, o U. S Patriot Act' (Ato Patriótico

\footnotetext{
${ }^{3}$ Resumidamente essa lei punia com severidade o apoio a terroristas, estabelecendo medidas rigorosas contra imigrantes suspeitos de terrorismo e controles mais amplos sobre a lavagem de dinheiro. Ampliou também a competência dos serviços de informação sobre a vigilância de pessoas,
} 
Americano) que ampliou os poderes do FBI, da polícia federal norte-americana, e de outras agências de manutenção da ordem.

Tal lei, renovada pelo Congresso em março de 2006, deu ao governo norteamericano poder para conduzir operações em sigilo, reprimir manifestações, colocar pessoas sob vigilância (mesmo sem qualquer prova que justifique a suspeita) ou recolher, com o objetivo de levar adiante uma investigação, informações confidenciais sobre a vida privada de cidadãos norte-americanos, bem como de estrangeiros residentes nos Estados Unidos.

A partir de então, o mundo passou a assistir a uma série de políticas norteamericanas que, a pretexto de combater o terrorismo, incidiam em arbitrariedades. As inspeções nos aeroportos se tornaram mais cuidadosas e menos preocupadas em não dispensar tratamentos discriminatórios, os consulados mais rigorosos na concessão de vistos, a administração mais agressiva no encalço dos imigrantes ilegais etc.

Os norte-americanos bombardeados pelo medo, com exceção de alguns poucos democratas e militantes por direitos civis, aceitaram a restrição de liberdade, legitimando o exercício arbitrário da violência quase sem limites por parte do Estado através do controle penal. Em nome da luta contra o terrorismo o governo também prendeu cidadãos de várias partes do mundo por tempo indeterminado e sem qualquer acusação formal. A base militar de Guantánamo $0^{4}$ e a prisão de Abu Ghraib, por exemplo, funcionaram como verdadeiros campos de concentração, acumulando encarcerados constantemente torturados ${ }^{5}$, servindo como símbolo de intimidação para todo o mundo.

bem como a permuta dos resultados apurados entre as diversas agências. Além disso, a lei permitia a revista domiciliar sem mandado judicial, ainda que na ausência do proprietário ou locatário. Mais informações sobre o tema podem ser encontradas em German (2002).

${ }^{4}$ De acordo com o relatório da Anistia Internacional, estavam detidas em Guantánamo, até 0 ano de 2006, cerca de 500 pessoas que, na prática, foram seqüestradas em seus países. Acusados informalmente de terem ligações com o regime do Talibã no Afeganistão, ou com a rede terrorista Al-Qaeda, esses presos viviam em condições desumanas. Sobre o tema confira: Guantánamo: Lives torn apart: the impact of indefinite detention on detainees and their families (em tradução livre, Guantánamo: Vidas despedaçadas - 0 impacto da prisão por tempo indefinido em detentos e seus familiares) (AMNESTY INTERNATIONAL, 2006).

${ }^{5}$ Segundo Maestri Filho (2006), os prisioneiros foram encarcerados, inicialmente no Campo X-Ray de Guantánamo, em jaulas de malha arame, de dois metros por três. Atados pelas mãos e pés, olhos, boca e ouvidos tapados, foram submetidos, por longos intervalos, a espancamentos, altas e baixas temperaturas, ruídos infernais e privação de sono. Sem direito a contatos pessoais, receberam injeções paralisantes, medicação forçada e alimentação violenta quando ensaiavam atos de resistência. Responsável por Guantánamo na época, o general Geoffrey Miller definiu o princípio geral que regia a prisão: "Eles são como cães, e se você os deixa acreditar em algum 
Apenas em 2009, com o fim da era Bush, esse cenário deu sinais de que poderia mudar. Dois dias após assumir o cargo, Barack Obama assinou uma ordem executiva para o fechamento da prisão de Guantánamo em até um ano. Porém, a ruptura com as políticas da era Bush não foi assim tão incisiva. Isso porque além do fechamento não ter acontecido, ainda permanecia em Guantánamo, no fim daquele ano, cerca de 245 prisioneiros ${ }^{6}$ sem acusação formal, apenas detidos por suposta ligação com o terrorismo internacional.

Em 25 abril de 2011 os jornais ${ }^{7}$ El País, The New York Times e Washington Post publicaram uma série de documentos secretos, revelados pelo site Wikileaks, que traziam informações detalhadas sobre a base militar norte-americana de Guantánamo. Com datas entre v2002 e 2009, os registros relatavam que 0 governo dos Estados Unidos usou a prisão de Guantánamo ilegalmente para obter informação dos detidos, independentemente de serem suspeitos ou não. Informavam também que parte dos prisioneiros afegãos e paquistaneses era inocente, incluindo

momento que são mais do que cães, então você perdeu controle sobre eles".

${ }^{6}$ Barack Obama prometeu tirar de Guantánamo esses 245 presos que permaneciam presos no local, porém, o problema era o que fazer com eles. 0 governo tinha que decidir se, uma vez fechada a prisão, os detentos que ali permaneciam seriam julgados por tribunais militares, processados em tribunais federais nos EUA ou detidos de forma indefinida. 0 partido republicano acusou Obama de pôr em perigo a segurança do país caso tais prisioneiros fossem levados a solo americano para julgamento, por considerar que o país poderia voltar a ser alvo dos terroristas. Mesmo o Congresso, de maioria democrata, negou fundos para fechar a prisão sem um plano mais detalhado sobre 0 destino dos detidos. Por fim, as transformações que o presidente queria implementar acerca das detenções de suspeitos de terrorismo não eram livres de controvérsia. Uma das mais polêmicas era a manutenção de detidos sem julgamento por tempo indeterminado. Eram presos que não podiam ser julgados nem em tribunais federais nem em comissões militares, mas que tampouco podiam ser libertados, pois o governo os considerava como ameaças ao país. "Não soltaremos ninguém que ponha em risco nossa segurança nacional", afirmou Obama naquele momento. 0 governo, declarou o presidente, terá que criar um marco legal específico para lidar com esses presos. "Tenho que ser honesto; essa é a questão mais difícil que enfrentaremos. Temos que ter padrões claros, defensáveis e legais para aqueles que caem nessa categoria, para que não cometamos erros. Temos que ter um processo detalhado de revisão para que cada detenção prolongada seja cuidadosamente avaliada justificada”. Ativistas aliados expressaram decepção: "Obama se envolveu na Constituição e então começou a violá-la ao anunciar que criaria um esquema de detenções preventivas que serve apenas para mudar Guantánamo de lugar e dar um outro nome", disse Michael Ratner, do Centro de Direitos Constitucionais de Nova York (MURTA, 2009).

7 Mais detalhes sobre as publicações confira: http://g1.globo.com/mundo/noticia/2011/04/ wikileaks-e-jornais-divulgam-arquivos-secretos-sobre-guantanamo.html. 
adolescentes, idosos, doentes mentais, motoristas, agricultores e cozinheiros, que foram detidos durante operações de inteligência em zonas de guerra.

Atualmente cerca de 170 pessoas continuam detidas em Guantánamo e, ao que tudo indica, reverteram-se radicalmente os esforços políticos para 0 fechamento de tal base militar. Segundo Belasco (2011):

[...] o governo norte-americano iniciou uma campanha de propaganda dentro dos EUA, primeiramente, e em seguida no mundo inteiro, com objetivo de "valorizar" o assassinato de Osama Bin Laden pelos comandos norte-americanos, a fim de legalizar perante a opinião pública mundial o funcionamento do vergonhoso campo de concentração de Guantánamo.

0 fato é que autoridades do governo Obama sustentam que o assassinato de Bin Laden não teria sido possível sem informações dos presos no campo de Guantánamo. (BBC BRASIL, 2011). Como ressalta Maestri Filho (2006), a função principal de Guantánamo é explicitar a prerrogativa norte-americana de negar os direitos humanos e civis mínimos, de qualquer cidadão, segundo suas necessidades.

Tais detenções por tempo indeterminado e sem acusações formais, segundo Agamben (2004, p. 14), "anulam radicalmente todo estatuto jurídico do indivíduo, produzindo, dessa forma, um ser juridicamente inopinável e inclassificável”. Ainda segundo o autor:

Os talibãs capturados no Afeganistão, além de não gozarem do estatuto de "prisioneiros de guerra" de acordo com as convenções de Genebra, também não gozam do estatuto de acusado segundo as leis norte-americanas. Nem prisioneiros, nem acusados, senão apenas detainees, são objeto de uma pura dominação de fato, de uma detenção indeterminada não apenas no sentido temporal, mas também com relação à própria natureza porque totalmente fora da lei e do controle judicial. A única comparação possível é com a situação jurídica dos judeus nos Lager nazistas: junto com a cidadania, haviam perdido toda identidade jurídica, embora pelo menos conservassem a identidade de judeu. Como Judith Butler claramente demonstrou, no detainee de Guantánamo a vida nua alcança sua máxima indeterminação (AGAMBEN, 2004, p. 14).

Constata-se, portanto, que a norma, instrumento liberal de controle, não se mostra mais suficiente para manter a ordem burguesa e, nesse contexto sua violação ou alteração constante é difundida como um mal necessário. Não sem razão, nos EUA e em alguns países europeus (Inglaterra, Espanha e Itália, 
principalmente) essas ilegalidades parecem não abalar a legitimidade da noção de democracia presente em suas culturas.

Ao contrário, uma cruzada democrática pelo mundo foi patrocinada por esses países e realizada com extrema violência que nada perdem para as cruzadas religiosas medievais. Mesmo assim justificam as guerras preventivas travadas como defesas dos valores democráticos, ainda que objetivos econômicos sejam observados; tudo a demonstrar que ao flexibilizar a noção de democracia ${ }^{8}$ perde-se totalmente o seu valor.

Para Agamben (2004, p. 29), é cada vez mais evidente a aceitação social de uma proteção absoluta à democracia ameaçada. Essa democracia tutelada, ou protegida, faz uso recorrente de mecanismos autoritários. Ainda, segundo o autor, "uma 'democracia protegida' não é uma democracia”, uma vez que "o paradigma da 'ditadura constitucional' funciona, sobretudo, como uma fase de transição que leva fatalmente à instauração de um regime totalitário".

0 próprio assassinato de Osama Bin Laden, perpetrado por meio de uma operação militar norte-americana realizada abruptamente no Paquistão, demonstra as faces dessa "política de exceção" travada na contemporaneidade. Nomeado midiaticamente como o mais perigoso dos terroristas, Bin Laden foi executado sumariamente. Princípios democráticos como o devido processo legal, da ampla defesa e do contraditório foram literalmente desprezados. Como destaca Zuin (2010, p. 63), a guerra passou a ser o "meio permanente de resolução dos conflitos globais".

Tal assassinato foi noticiado na televisão em cadeia nacional pelo próprio presidente Barack Obama e logo após o seu pronunciamento, multidões saíram às

\footnotetext{
${ }^{8}$ Conceitos dos mais controvertidos na teoria política, democracia e autoritarismo, embora contraditórios, permanecem associados no ocidente capitalista permitindo a manutenção da estrutura política a serviço dos novos interesses liberais. Se de fato Sartori $(1994$, p. 17, v. 1) está correto ao afirmar que "entre as condições da democracia, a menos lembrada é que idéias erradas sobre ela a fazem dar errado", Santos (2003) procura identificar os erros propondo "democratizar a democracia". Mesmo no capitalismo, em que a democracia, determinada pela estrutura do Estado burguês, estabelece as condições políticas da dominação de classe, "uma política de esquerda que venha a obter sucesso no interior dessa democracia poderá minimizar os efeitos reprodutivos favoráveis à ordem social dominante" (FARIAS, 2000). De fato, não há como imaginar a democracia como suficiente para mudar a estrutura social classista e exploratória. Contudo, conforme proferiu Enrico Berlinguer, secretário-geral do Partido Comunista Italiano em 1977, em um ambiente político não autoritário, "o adversário de classe é, por vezes, obrigado a retroceder" (COUTINHO, 1980, p. 20).
} 
ruas para comemorar. Aos gritos e carregando bandeiras, o povo americano deu 0 seu recado: Talião ${ }^{9}$ nunca foi tão atual.

\section{Medo e estado Punitivo}

Nessa toada, ao contrário do discurso moderno de controle democrático, cuja concepção básica era a reforma e a intervenção social para prevenir e combater o desvio, a atual forma de conceber as políticas de controle abandona a perspectiva humanista de respeito às garantias jurídicas nacionais e internacionais, para focalizar a simples imposição de mecanismos de retribuição e aniquilação.

Durante uma boa parte do século XX, a expressão abertamente confessada do sentimento de vingança foi virtualmente tabu, pelo menos da parte dos representantes do Estado, mas, nesses últimos anos, tentativas explícitas de expressar a cólera e o ressentimento do público tornaram-se um tema recorrente da retórica que acompanha a legislação penal e a tomada de decisões. Os sentimentos da vítima, ou da família da vítima, ou um público temeroso, ultrajado, são agora constantemente invocados em apoio a novas leis e políticas penais. 0 castigo - no sentido de uma sanção significativa que apela para o sentimento do público — é uma vez mais um objetivo penal respeitável, abertamente reivindicado (GARLAND, 1999, p. 62).

Sob esse novo prisma, a política interna, relacionada ao controle de qualquer violência, principalmente a considerada terrorista, deixa de ser preventiva e passa a ser predominantemente repressiva. A política externa de resolução de conflitos por sua vez, abandona paulatinamente a orientação pacífica (diplomática) e assume cada vez mais a postura combativa traduzida em respostas militares agressivas.

Não é por outra razão que parlamentares britânicos expressaram preocupação em um relatório recente. Segundo o documento, a morte de 0sama Bin Laden poderia abrir um precedente para assassinatos cometidos por Estados no futuro. "A natureza do assassinato de Bin Laden poderia ser sinal de que os EUA teriam tendência cada vez maior de matar membros da Al Qaeda do que capturálos". [...] "Uma implicação maior é que a morte poderia ser vista como precedente

\footnotetext{
${ }^{9} 0$ princípio talional, expresso pela primeira vez no Código de Hamurabi, aparece em vários textos jurídicos da Antiguidade. Tal principio prega a proporcionalidade da punição, vale dizer, uma equação adequada entre a conduta delitiva e a reação punitiva. Hoje a lei de Talião é mais associada à idéia de vingança e difundida principalmente pela expressão bíblica "alma por alma, olho por olho, dente por dente, mão por mão, pé por pé, queimadura por queimadura, ferimento por ferimento, pancada por pancada" (Êxodo 21:24).
} 
para 0 assassinato de indivíduos por qualquer país, além de fronteiras nacionais, pelo menos quando envolver terrorismo." (EFE, 2011).

Ainda assim, Ban Ki-moon, secretário-geral da ONU, afirmou sentir-se aliviado após a morte do líder da rede terrorista Al Qaeda. "Sinto-me aliviado por ter sido feita justiça com este inspirador do terrorismo", disse o secretário-geral em entrevista coletiva em Genebra. (BBC BRASIL, 2011). Esquece, contudo, o secretário que essa vingança privada não se coaduna com o Estado democrático de Direito, jamais podendo ser concebida como justiça.

Impregnados pelo medo e pela ira, muitos americanos eufóricos com 0 assassinato de Osama Bin Laden acabaram simbolizando os valores e os sentimentos desse estágio da modernidade: insegurança, intolerância e ressentimento. Visíveis e reconhecíveis tanto na esfera privada quanto na pública esses símbolos representam e explicam as dinâmicas sociais perversas, truculentas e aniquiladoras que assistimos atualmente.

Esses símbolos atravessam o atlântico disseminando o medo generalizado em praticamente todo o ocidente. Terrorismo, crime organizado e violência passam a figurar no imaginário social de forma confusa, muitas vezes como sinônimos de sociopatias motivadas por desvios de personalidade ou relacionadas à religião como o caso dos fundamentalismos. Tratados como distúrbios sociais, os eventos violentos quase nunca são associados à política, seja ela interna ou internacional. Retratados pela grande mídia como rompantes furiosos, a violência, fruto ou não de atos terroristas, é compreendida como atitude imoral e injusta a merecer dura e imediata reprimenda.

0 fato é que não conseguimos compreender as razões desses eventos violentos que muitas vezes estão associados às decisões políticas que mudaram 0 rumo da economia em escala global. Até os ataques que manifestamente se opõem a forças imperialistas são retratados como histerias coletivas ou como fanatismos religiosos. Mesmo conflitos internos como motins ${ }^{10}$, saques e depredações são

\footnotetext{
${ }^{10}$ A onda de revolta ocorrida no Reino Unido, em agosto de 2011 é um exemplo emblemático dessa realidade. Embora não exista vínculo algum entre tais distúrbios e qualquer noção que se aproxime das conceituações acerca do terrorismo contemporâneo, tais eventos foram tratados como irracionalidades e incivilidades merecedoras de reprovação exemplar, contundente e imediata. Contudo, mesmo a mídia reduzindo o conflito a mero vandalismo sem justificativa, a realidade britânica atesta um alto índice de desemprego entre os jovens e um baixíssimo investimento em políticas sociais capazes de reverter os efeitos negativos desse contexto. A fúria avassaladora assistida pelos britânicos e a atitude externada pelo governo diante das manifestações violentas, com inúmeras prisões e condenações sumárias e exemplares, atestam a tendência contemporânea de criminalização da miséria.
} 
muitas vezes traduzidos como barbáries e indícios de anomia. Revoltas populares que não adquirem apoio internacional ${ }^{11}$ costumam ser interpretadas pelos órgãos governamentais e, tratadas midiaticamente, como distúrbios inaceitáveis e inexplicáveis. Contra todo esse cenário difuso de violência a opção política recorrente tem sido a supressão de direitos e a retórica maniqueísta de severidade e intolerância.

Os perigos que mais tememos são imediatos: compreensivelmente, também desejamos que os remédios o sejam - "doses rápidas"; oferecendo alívio imediato, como analgésicos prontos para o consumo. Embora as raízes do perigo possam ser dispersas e confusas, queremos que nossas defesas sejam simples e prontas a serem empregadas aqui e agora. Ficamos indignados diante de qualquer solução que não consiga prometer efeitos rápidos, fáceis de atingir, exigindo em vez disso um tempo longo, talvez indefinidamente longo, para mostrar resultados. Ainda mais indignados ficamos diante de soluções que exijam atenção às nossas próprias falhas e iniqüidades, e que nos ordenem, ao estilo de Sócrates, que "conheça-te a ti mesmo"! (BAUMAN, 2008, p. 149).

Nesse contexto, o controle da transgressão violenta se pretende absoluto De acordo com Wacquant (2001, p. 7), a "penalidade neoliberal apresenta o seguinte paradoxo: pretende remediar com um 'mais Estado' policial e penitenciário 0 'menos Estado' econômico e social que é a própria causa da escalada generalizada da insegurança objetiva e subjetiva em todos os países”.

Essa penalidade reafirma a onipotência do Leviatã no que se refere à manutenção da ordem pública, simbolizada pela "guerra contra o crime", reforçando a legitimidade de posturas autoritárias comprometidas com o sucesso do atual empreendimento liberal.

Os medos lá estão, saturando a vida cotidiana dos seres humanos na medida em que a desregulamentação do globo atinge seus alicerces mais profundos e os bastiões defensivos da sociedade civil se desmantelam. Os medos estão lá, e recorrer a seus suprimentos aparentemente inesgotáveis e auto-reprodutíveis a fim de reconstruir um capital político exaurido é uma tentação a que muitos políticos consideram difícil de resistir. Bem antes do 11 de Setembro, entregar-se a tal tentação, juntamente com seus formidáveis benefícios, era

\footnotetext{
${ }^{11}$ As inúmeras manifestações populares iniciadas no Egito, em janeiro de 2011, e apelidadas de Primavera Árabe, por exemplo, não foram representadas midiaticamente como distúrbios. Ao contrário, embora questionáveis os motivos, a imprensa internacional ratificou o apoio da Organização do Tratado do Atlântico Norte (OTAN) e de países como os Estados Unidos, Inglaterra e França aos insurgentes, inclusive legitimando a prática de ações armadas.
} 
algo que já tinha sido bem ensaiado e testado. Em um estudo que recebeu 0 título, ao mesmo tempo adequado e mordaz, de "The Terrorist, Friend of State Power" [0 terrorista, amigo do poder do Estado], Victor Grotowicz analisou os usos, pelo governo da República Federal da Alemanha, dos atentados terroristas perpetrados pela Faç̧ão do Exército Vermelho numa época em que os "trinta anos gloriosos" do Estado social "começavam a mostrar os primeiros sinais de proximidade do fim". Ele descobriu que, enquanto em 1976 apenas 7\% dos cidadãos alemães consideravam a segurança pessoal como um assunto político importante, dois anos depois uma considerável maioria daquela população achava esse tema mais relevante do que a luta contra o desemprego crescente e a inflação galopante. Durante aqueles dois anos a nação assistiu pelas telas de TV a imagens que mostravam as forças em rápida expansão da polícia e do serviço secreto, e ouviu as propostas, cada vez mais audaciosas, de políticos que tentavam sobrepujar um ao outro ao prometerem medidas sempre mais duras e severas a serem empregadas na guerra total contra os terroristas (BAUMAN, 2008, p. 198-199).

A partir dessas representações, muitas sociedades, tomadas pela obsessão securitária, voltam-se para seus transgressores com fúria e como profilaxia para a violência exigem soluções severas e infalíveis. A atuação estatal, por sua vez, baseia-se na noção de emergência, entendida como um momento excepcional a exigir "uma resposta pronta e imediata, que deve durar enquanto o estado emergencial perdure.” (BECK, 2004, p. 95). Essa noção de emergência, alimentada pelo medo social constante e estrategicamente introjetado, transforma os conflitos em ameaças e torna fácil desviar o cerne dos problemas, que não é de natureza conjuntural, mas social.

De acordo com Wacquant, "a inconteste hegemonia do pensamento neoliberal sobre segurança dos dois lados do Atlântico" associou a "'mão invisível' do mercado do trabalho desqualificado com o seu prolongamento ideológico e seu complemento institucional no 'punho de ferro' do Estado penal" (WACQUANT, 2007, p. 40).

Essa marca ostensiva relacionada ao controle une todos os setores do Estado em um único discurso e em uma ação coordenada que, de forma implacável, fragiliza significativamente 0 ambiente democrático. Nesse contexto, a gestão da segurança pública é "concebida e executada não tanto por ela mesma, mas sim com a finalidade expressa de ser exibida e vista, examinada e espionada: a prioridade absoluta é fazer dela um espetáculo, no sentido próprio do termo" (WACQUANT, 2007, p. 9). 
Quando o tema é política externa, a tendência é ignorar o direito internacional rejeitando as tradicionais formar judiciais e diplomáticas de resolução de conflitos. A intervenção militar, o desrespeito à soberania e, no limite, a própria guerra preventiva passam a figurar como alternativas cada vez mais legítimas no cenário mundial. Sobre o tema, Kennedy apresenta seu prognóstico pessimista:

Agora a identificação das redes terroristas como o maior inimigo da América e a aceitação de todos os governos que ajudem a esmagá-las podem criar um critério dúbio e contraproducente para a diplomacia a longo prazo. Grandes potências que impõem maus-tratos a suas minorias étnicas e religiosas a Rússia na Chêchenia e a China no Tibete e em Xinjianang - podem ser indultadas, ou pelo menos seus atos podem ser ignorados. Países que eram vistos com desagrado e desconfiança - basta pensar no homicida regime sudanês - talvez sejam recompensados caso se posicionem contra o terrorismo internacional (KENNEDY apud TALBOTT; CHANDA, 2002, p. 87-88).

0 Conselho de Segurança da ONU e o Tribunal Penal Internacional, por exemplo, estão fragilizados e não conseguem mais estabelecer suas prerrogativas com razoável credibilidade. A manutenção da paz e o combate aos crimes contra a humanidade são pautas que sucumbem frente à "guerra ao terror".

Como se observa, incorporado ao tema da manutenção da democracia, o combate ao desvio ganha positividade como peça do grande consenso presente na uniformização dos valores políticos, morais e sociais contemporâneos. Esse discurso ganha cada vez mais legitimidade e, de forma paradoxal, associa-se à defesa da democracia.

\section{CONSIDERAÇÕES FINAIS}

Ao estudar o medo contemporâneo associado ao terrorismo, extrai-se que atualmente a dominação política por vezes se efetiva diluindo a opressão em contextos instáveis. Inserido em ambiente propagado como hostil e temerário, o cidadão acaba por aceitar que preço de sua segurança é a arbitrariedade e 0 autoritarismo. De fato, uma das formas mais eficazes de dominação é a de criar uma ideologia justificadora, que faz com que todo ato autoritário seja visto como circunstancial e necessário. Embora sempre simbólica, essa dominação se efetiva de várias maneiras. A mais comum é certamente o uso político do medo (PASTANA, 2003).

Em primeiro lugar, o terrorismo funciona. A violência também. Em seguida, é um equívoco pensar que o terrorismo seria o instrumento dos fracos. Como 
a maioria das armas mortíferas, o terrorismo é, antes de tudo, a arma dos poderosos. Quando se diz o contrário, é unicamente porque os poderosos controlam também os aparelhos ideológicos e culturais, que permitem que o terror deles seja visto como uma coisa diferente do terror. Um dos meios mais comuns de que dispõem para chegar a tal resultado é fazer com que acontecimentos incômodos desapareçam da memória; assim, mais ninguém se lembra deles (CHOMSKY, 2001).

Em grande parte do ocidente capitalista, a elite dirigente se utiliza do medo da violência para convencer o cidadão a aceitar um controle mais ostensivo. Essa violência estatal, travestida de luta democrática contra o terror, consegue aglutinar realidades absolutamente diferentes e o discurso rigoroso acaba convencendo sociedades pouco atingidas pelo terrorismo que elas também estão a correr perigo.

Ressentimentos gerados globalmente flutuam no espaço global tão facilmente quanto as finanças ou a última moda em música ou roupas, e assim também o impulso de vingança em relação aos genuínos ou supostos culpados, ou ainda (se estes forem inacessíveis) aos bodes expiatórios mais adequados e convenientes (BAUMAN, 2008, p 161-162).

Nesse cenário, tanto atos considerados terroristas, como rompantes de fúria vivenciados por grupos variados, são tratados com violências injustificadas. Toda e qualquer violência passa a ser tratada com "punhos de ferro".

A percepção de um público amedrontado e revoltado teve grande impacto no tipo e no conteúdo das políticas, nos anos recentes. 0 crime foi redramatizado. A imagem aceita, própria da época do bem-estar, do delinqüente como um sujeito necessitado, desfavorecido, agora desapareceu. Em vez disto, as imagens modificadas para acompanhar a nova legislação tendem a ser esboços estereotipados de jovens rebeldes, de predadores perigosos e de criminosos incuravelmente reincidentes, Acompanhando estas imagens projetadas, e em reação retórica a elas, o novo discurso da política criminal insistentemente invoca a revolta do público, cansado de viver com medo, que exige medidas fortes de punição e de proteção. 0 mote aparente da política é agora mais a revolta coletiva e o justo reclamo por retribuição do que um compromisso com a construção de soluções sociais justas (GARLAND, 2008, p. 54).

Tais constatações nos remetem aos polêmicos e radicais ensinamentos de Schmitt (2006). Quando a estabilidade política e a segurança nacional são ameaçadas por um evento imprevisto, considerado, ou divulgado, como de 
extrema gravidade, "o soberano se coloca fora da ordem jurídica normalmente vigente, ainda que a ela pertença, pois é competente para decidir se a Constituição pode ser suspensa in Toto" (sic) (SCHMITT, 2006, p. 7-8).

Desse contexto que emergem também, na contemporaneidade, as preleções de Jakobs e Cancio Meliá (2003) sobre um Direito Penal do Inimigo. Segundo o autor os inimigos contemporâneos seriam tanto os terroristas quanto os criminosos econômicos, os delinqüentes organizados, os autores de delitos sexuais e outros infratores penais perigosos (JAKOBS; CANCIO MELIÁ, 2003,p. 39). Em outras palavras, é inimigo quem se desvia permanentemente do Direito recusando-se a retornar ao fiel cumprimento da norma. Jakobs e Cancio Meliá (2003) citam, inclusive, o emblemático 11 de setembro de 2001 como ato inequívoco de um inimigo. Ainda segundo o autor, os inimigos atuais não devem ser tratados como cidadãos, não sendo sujeitos processuais. "Cabe ao Estado não reconhecer seus direitos, ainda que de modo juridicamente ordenado" (JAKOBS; CANCIO MELIÁ, 2003, p. 45). Contra 0 inimigo não há devido processo legal, ao contrário declara-se guerra.

Essa pode ser também a imagem do "Estado de Exceção" retratado por Agamben (2004, p. 76) ao apontar sua "preocupação com a escalada das práticas de controle; com o fato de medidas excepcionais estarem se tornando normais". Ainda, segundo o autor, "provavelmente está se aproximando o momento em que todos os cidadãos serão 'normalmente' controlados pelo estado do modo que antes se usava somente para criminosos, nas prisões" (AGAMBEN, 2004, p. 76).

Diante de tal violência institucional, reacendem-se ânimos perigosos como nacionalismos e mesmo terrorismos. Esse movimento político é, portanto, ao mesmo tempo, bombeiro e incendiário.

E o terrorismo?

0 que é terrorismo? [...] Existe uma resposta fácil para esta pergunta, uma definição oficial. Podemos encontrá-la na legislação norte-americana ou nos manuais do exército. Uma breve definição, extraída de um manual do exército norte-americano, diz que "terror é 0 uso premeditado da violência ou da ameaça de violência para atingir metas ideológicas políticas ou religiosas mediante intimidação, coerção ou instilação do medo". Isso é terrorismo. [...]. Se examinarmos a definição de "guerra de baixa intensidade", que é a política oficial dos Estados Unidos, veremos que é uma paráfrase bastante próxima do que acabei de ler. Na realidade, "conflito de baixa intensidade" é apenas um outro nome para terrorismo. É por isso que, pelo que sei, todos os países designam de contraterrorismo quaisquer atos horrendos que estejam 
cometendo. Nós chamamos isso de contra-insurgência ou conflito de baixa intensidade. É um problema grave (CHOMSKY, 2002).

Enfim, podemos perceber que a resposta americana aos eventos ocorridos em 11/09 de 2001 também se encaixam na sua definição militar de terrorismo. De fato, todas as medidas tomadas, extremamente violentas e destrutivas, provocaram mortes e desordens em países já fragilizados com seus problemas locais. 0 medo da revanche também monopolizou o imaginário do mundo árabe alterando significativamente suas relações sociais após os eventos de 2001.

Se os ataques de 11 de setembro foram um evento histórico, a mudança mais significativa no mundo é certamente a configuração de um momento de medo, ódio e vingança.

0 discurso político passou a ser revanchista e extremamente alarmista. Verifica-se, portanto, que o medo e a insegurança não têm raízes diretas nas revoltas populares e mesmo no terrorismo. 0 medo surge de uma utilização políticoideológica da insegurança, e se solidifica em um ambiente de desorganização social, alienação e desconfiança. 0 que significa que os dois problemas, terror e medo, não se condicionam reciprocamente. A confusão, nesse caso, "serve às ideologizações, mas jamais à elaboração de políticas eficientes” (SOARES et al., 1996).

Compreender essa nova configuração política, mais combativa frente aos conflitos sociais e pouco preocupada em questionar a origem dos mesmos, é de fundamental importância para as Ciências Sociais na medida em que permite desvendar as atuais tendências autoritárias hegemonicamente articuladas em praticamente todo o globo.

Para finalizar é oportuna também a observação de Chomsky (2005): "todos se preocupam em deter o terrorismo. Bem, há uma maneira realmente simples: parem de participar dele".

\section{REFERÊNCIAS}

AGAMBEN, Giorgio. Estado de exceção. São Paulo: Boitempo, 2004.

AMNESTY INTERNATIONAL. Guantánamo: Lives torn apart: the impact of indefinite detention on detainees and their families. 2006. Disponível em: < http:// www.amnesty.org.nz/files/lives-torn-apart.pdf>. Acesso em: 13 out. 2011.

BAUMAN, Zygmunt. 0 medo líquido. Rio de Janeiro: Jorge Zahar, 2008. 
BBC BRASIL. Morte de Bin Laden pode abrir precedente internacional, diz relatório. O Estado de São Paulo, São Paulo, 17 maio 2011. Disponível em: $<$ http://www.estadao.com.br/noticias/internacional,morte-de-bin-laden-podeabrir-precedente-internacional-diz-relatorio-britanico,720428,0.htm>. Acesso em: 15 out. 2011.

BECK, Francis Rafael. Perspectivas de controle ao crime organizado e críticas à flexibilização de garantias. São Paulo: IBCCRIM, 2004.

BELASCO, Pedro. 0 Guantánamo de Barack Obama. Monitor Mercantil, São Paulo, 12 maio 2011. Disponível em: <http://www.outroladodanoticia.com.br/ inicial/14378-o-guantanamo-de-barack-obama.html>. Acesso em: 13 out. 2011 CHOMSKY, Noam. Terrorismo, a arma dos poderosos. Le Monde Diplomatique, Brasil, 1 dez. 2001. Disponível em: <http://diplomatique.uol.com.br/acervo.php? $\mathrm{id}=346 \&$ tipo $=$ acervo\&PHPSESSID $=2992 \mathrm{afb} 2 \mathrm{~cd} 65 \mathrm{c} 8594 \mathrm{faad} 2 \mathrm{ff} 286459 \mathrm{fc}>$ Acesso em: 13 out. 2011.

. A nova guerra contra o terror. Revista Estudos Avançados, São Paulo, v. 16, n. 44, p. 5-33, 2002.

. Poder e terrorismo. Rio de Janeiro: Record, 2005.

COUTinHo, Carlos Nelson. A democracia como valor universal. São Paulo: Ciências Humanas, 1980.

DELUMEAU, Jean. História do medo no ocidente: 1300-1800. São Paulo: Companhia das Letras, 1999.

EFE. Justiça foi feita, diz líder da ONU sobre morte de Bin Laden. Folha de São Paulo, São Paulo, 11 maio 2011. Disponível em: < http://wwwl.folha.uol.com. br/mundo/914170-justica-foi-feita-diz-lider-da-onu-sobre-morte-de-bin-laden. shtml>. Acesso em: 15 out. 2011.

FARIAS, Francisco Pereira de. Clientelismo e democracia capitalista: elementos para uma abordagem alternativa. Revista de Sociologia e Política, Curitiba, n. 15, p. 49-65, nov. 2000.

GARLAND, David. As contradições da 'sociedade punitiva': o caso britânico. Revista de Sociologia e Política, Curitiba, n. 13, p. 59-80, nov. 1999.

. A cultura do controle: crime e ordem social na sociedade contemporânea. Rio de Janeiro: Ed. Revan, 2008. 
GERMAN, Chistiano. As novas leis de segurança na Alemanha e nos Estados Unidos: os efeitos para a comunicação local e global. Revista CEJ, Brasília, n. 19, p. 78-84, out./dez. 2002.

HOBSBAWM, Eric. Globalização, democracia e terrorismo. São Paulo: Companhia das letras, 2010.

JAKOBS, Günter; CANCIO MELIÁ, Manuel. Derecho penal del enemigo. Madrid: Civitas, 2003.

LAQUEUR, Walter. Postmodern terrorism: new rules for an old game. 1996. Disponível em: <http://www.foreignaffairs.org > Acesso em: 16 out. 2011.

MAESTRI FILHO, Mário José. Guantánamo: a honra ofendida da humanidade. Correio da Cidadania, São Paulo, p. 2-3, mar. 2006.

MURTA, Andrea. Obama quer "limpar bagunça" de Guantánamo. Folha de São Paulo, São Paulo, 22 maio 2009. Editoria Mundo Disponível em:_<http://www1. folha.uol.com.br/fsp/mundo/ft2205200901.htm>. Acesso em: 15 out. 2011.

PASTANA, Debora Regina. Cultura do medo: reflexões sobre violência, controle social e cidadania no Brasil. São Paulo: Método, 2003.

SANTOS, Boaventura de Souza (Org.). Democratizar a democracia: os caminhos da democracia participativa. 2. ed. Rio de Janeiro: Civilização Brasileira, 2003.

SARTORI, Giovanni. A teoria da democracia revisitada: o debate contemporâneo. São Paulo: Ática, 1994. v. 1.

SCHMITT, Carl. Teologia política. Belo Horizonte: Del Rey, 2006.

SOARES, Luiz Eduardo et al. Uma radiografia da violência no Rio de Janeiro. In: BENGEMER, Maria ClaraLucchetti; BARTHOLO JUNIOR, Roberto dos Santos. Violência, crime e castigo. Rio de Janeiro: Loyola, 1996. p. 85-116.

TALBOTT, Strobe; CHANDA, Nayan (Org.). A era do terror: o mundo depois de 11 de setembro. Rio de Janeiro: Campus, 2002.

WACQUANT, Loïc. As prisões da miséria. Rio de Janeiro: Jorge Zahar, 2001.

. Punir os pobres: a nova gestão da miséria nos EUA. Rio de Janeiro: Freitas Bastos, 2007.

ZUIN, João Carlos Soares. As contradições da globalização: os centros de confinamento para os imigrantes ilegais na Itália. Mediações: Revista de Ciências Sociais, Londrina, v. 15, n. 2, p. 61-77, 2010. 